\title{
Control of Crystal Morphology for Mold Flux During High-Aluminum AHSS Continuous Casting Process
}

\author{
JING GUO, MYUNG-DUK SEO, CHENG-BIN SHI, JUNG-WOOK CHO, \\ and SEON-HYO KIM
}

In the present manuscript, the efforts to control the crystal morphology are carried out aiming at improving the lubrication of lime-alumina-based mold flux for casting advanced high-strength steel with high aluminum. Jackson $\alpha$ factors for crystals of melt crystallization in multi-component mold fluxes are established and reasonably evaluated by applying thermodynamic databases to understand the crystal morphology control both in lime-alumina-based and lime-silica-based mold fluxes. The results show that Jackson $\alpha$ factor and supercooling are the most critical factors to determine the crystal morphology in a mold flux. Crystals precipitating in mold fluxes appear with different morphologies due to their different Jackson $\alpha$ factors and are likely to be more faceted with higher Jackson $\alpha$ factor. In addition, there is a critical supercooling degree for crystal morphology dendritic transition. When the supercooling over the critical value, the crystals transform from faceted shape to dendritic ones in morphology as the kinetic roughening occurs. Typically, the critical supercooling degrees for cuspidine dendritic transition in the lime-silica-based mold fluxes are evaluated to be between 0.05 and 0.06 . Finally, addition of a small amount of $\mathrm{Li}_{2} \mathrm{O}$ in the mold flux can increase the Jackson $\alpha$ factor and decrease the supercooling for cuspidine precipitation; thus, it is favorable to enhance a faceted cuspidine crystal.

DOI: $10.1007 / \mathrm{s} 11663-016-0697-7$

(C) The Minerals, Metals \& Materials Society and ASM International 2016

\section{INTRODUCTION}

DURING the casting of high-Al advanced highstrength steel (AHSS), the high Al content in molten steel can easily reduce $\mathrm{SiO}_{2}$ in mold flux, resulting in the variation in the chemistry of conventional lime-silica-based mold fluxes. This variation generally causes the instability of physical and chemical properties of mold flux, such as melting point, viscosity, basicity, and so on, which has been reported as the main reasons for various problems during casting of high-Al steels such as breakout, non-uniform heat transfer across mold flux, inadequate lubrication, and poor as-cast slab surface quality. ${ }^{[1-4]}$ Consequently, it is in urgent need to develop sound mold fluxes to meet the requirements

JING GUO, formerly Postdoctoral Fellow with the Department of Materials Science and Engineering, Pohang University of Science and Technology (POSTECH), Pohang 790-784, Republic of Korea, is now Assistant Professor with the School of Metallurgical and Ecological Engineering, University of Science and Technology Beijing (USTB), Beijing 100083, P.R. China. MYUNG-DUK SEO, Senior R\&PD Engineer, is with Casting \& Forging Business Group, Doosan Heavy Industries \& Construction, Changwon 642-792, Republic of Korea. CHENG-BIN SHI, Assistant Professor, is with the State Key Laboratory of Advanced Metallurgy, University of Science and Technology Beijing (USTB). JUNGWOOK CHO, Research Associate Professor, is with the Graduate Institute of Ferrous Technology, Pohang University of Science and Technology (POSTECH. Contact e-mail: jungwook@postech.ac.kr SEON-HYO KIM, Professor, is with the Department of Materials Science and Engineering, Pohang University of Science and Technology (POSTECH).

Manuscript submitted November 15, 2015.

Article published online May 31, 2016. of high-aluminum AHSS casting. Generally speaking, there are two strategies to attempt to solve this problem at present. The first is to use the mold flux with low basicity to inhibit the reduction rate of $\mathrm{SiO}_{2}$ during the continuous casting (CC) process. $^{[5-7]}$ Obviously, it cannot overcome the instability of mold flux properties during CC process completely by this method. Furthermore, it also increases the difficulties to control the stable silicon content of high-Al AHSS. As a result, to develop an optimized unreactive $\mathrm{CaO}-\mathrm{Al}_{2} \mathrm{O}_{3}$-based mold flux, the second strategy, is increasingly investigated by many researchers. ${ }^{[3,4,8-12]}$ Blazek et al. ${ }^{[3]}$ worked on lime-alumina-based mold flux for casting high-Al AHSS steel and showed that the interaction was markedly reduced and the as-cast slab quality was improved compared to that of lime-silica-based mold flux. Cho et al. ${ }^{[8]}$ carried out casting trials of high-Al TRIP steel by using the newly developed lime-alumina-based mold fluxes, and their results suggested that mold heat transfer in casting process and surface quality of slab were improved, compared to that of lime-silica-based mold fluxes as well. But their experimental results also demonstrated that lubrication and flux consumption of lime-alumina-based mold fluxes should be further improved for industrial applicability. In order to understand the causes of lubrication differences between lime-alumina-based mold fluxes and lime-silica-based mold flux further, more careful researches concerning on the crystallization behaviors had been carried out by the present authors, ${ }^{[13-16]}$ which demonstrated huge differences in crystal morphology between 
the foregoing two kinds of mold fluxes, as shown in Figure 1. For the $\mathrm{CaO}-\mathrm{SiO}_{2}$-based mold fluxes, the primary crystalline cuspidine $\left(\mathrm{Ca}_{4} \mathrm{Si}_{2} \mathrm{~F}_{2} \mathrm{O}_{7}\right)$ was typically faceted with moderate size in morphology generally, as shown in Figure 1(a). While two kinds of different primary crystals in morphology were observed for $\mathrm{CaO}-\mathrm{Al}_{2} \mathrm{O}_{3}$-based mold fluxes, i.e., massive blocky calcium aluminates and needle-like calcium borates, as shown in Figures 1(b) and (c), respectively. The latter two kinds of crystals increase the roughness of the interface between the mold flux and solidifying steel shell and between the flux and copper mold that is speculated as the main cause for poorer lubrication of $\mathrm{CaO}-\mathrm{Al}_{2} \mathrm{O}_{3}$-based mold flux than that of conventional $\mathrm{CaO}-\mathrm{SiO}_{2}$-based mold flux. As a matter of fact, the flux film between the solidifying steel shell and copper mold consists of a liquid layer and a solid layer. The properties of the solid layer, thus, would also play a role on the lubrication of the slag film. In order to improve the holistic lubrication of flux film, not only the liquid layer lubrication should be improved by decreasing its viscosity but that of the solid layer should be also promoted by controlling the crystallization behaviors, such as crystal fraction, size and morphology, and so on. For $\mathrm{CaO}-\mathrm{Al}_{2} \mathrm{O}_{3}$-based mold fluxes, since they are verified to have very strong crystallization ability, the lubrication improvement of the solid layer, thus, is more significant for the purpose of global lubrication improvement of flux film. Therefore, it is promising to improve the lubrication of $\mathrm{CaO}-\mathrm{Al}_{2} \mathrm{O}_{3}$-based mold fluxes for casting the high-Al AHSS by controlling the favorable crystal morphology similar to that of cuspidine crystal in traditional $\mathrm{CaO}-\mathrm{SiO}_{2}$-based mold flux since the later has been confirmed a relative admirable lubrication performance.

About the crystal morphology control, Jackson. ${ }^{[17,18]}$ firstly established a theory to predict and explain the solid-liquid interface morphology and proposed a parameter, named Jackson $\alpha$ factor, to predict the metal crystal morphology, and suggested that an interface would be faceted if $\alpha$ factor is greater than 2 (the value is reported as 3 by some other researchers ${ }^{[19,20]}$ ) and it would be non-faceted if the $\alpha$ factor is lower than the critical value. The classification has been considerably successful in the binary eutectic and compound metal solutions. ${ }^{[21,22]}$ In addition, Temkin ${ }^{[23,24]}$ considered the problem of the roughening transition of an interface in relation to the driving force as well as the Jackson $\alpha$ factor, and his results showed that on increasing the driving force, a smooth interface transformed into a rough interface: a kinetic roughening transition. Lu et al. ${ }^{[25]}$ reported the crystal morphology transition during different supercooling degrees of $\mathrm{Ni}$-Si alloy melt and their results demonstrated the crystal morphology of the alpha-Ni phase transformed from non-faceted to faceted in morphology when the supercooling was larger than approximating $390 \mathrm{~K}\left(390^{\circ} \mathrm{C}\right)$ due to the increase of Jackson $\alpha$ factor correspondingly, while it tended to be dendritic again when the surpercooling was greater than around $500 \mathrm{~K}\left(500{ }^{\circ} \mathrm{C}\right)$ due to the kinetic roughening. Heulens et al. ${ }^{[26]}$ observed crystal growth of wollastonite $\left(\mathrm{CaSiO}_{3}\right)$ in a $\mathrm{CaO}-\mathrm{Al}_{2} \mathrm{O}_{3}-\mathrm{SiO}_{2}$ melt in situ using a hot stage confocal laser scanning microscope (CLSM), and their results suggested that a faceted growth form was observed at $1643 \mathrm{~K}\left(1370{ }^{\circ} \mathrm{C}\right)$, while dendritic growth occurred at $1593 \mathrm{~K}\left(1320^{\circ} \mathrm{C}\right)$. Also, the effects of constitutional supercooling on the crystal morphology were also reported. ${ }^{[27-29]}$ However, to authors' best knowledge, there are so few available public results to understand the crystalline morphology control in multi-component mold fluxes.

In consideration of the great practical significance, the present investigation was carried out to understand how to control crystal morphology in mold flux as a successive work of our previous findings ${ }^{[13-16]}$ on both the lime-alumina-based and lime-silica-based mold fluxes. A thermodynamic method was introduced to estimate Jackson $\alpha$ factor of a crystal in multi-component mold fluxes and the parameters were calculated with the help of the thermodynamic databases of FactSage 6.4. Furthermore, the combined effects of Jackson $\alpha$ factor, undercooling and flux composition on crystal morphology in mold fluxes were discussed. It provides a very nice guidance of the composition design for the further development of lime-alumina-based mold flux for casting AHSS with high Al.

\section{THEORIES FOR CRYSTAL MORPHOLOGY CONTROL}

Jackson suggested a system in which the solid and liquid phases were separated by an interface with one-layer atom thickness, and he calculated the surface free energy changes as a function of the ratio of site occupancy of the constituent unit on the interface, as shown in Eq. [1]. The detailed derivation is referred to References 17 and 18

$$
\frac{\Delta F}{N k T}=X(1-X) \alpha+X \ln X+(1-X) \ln (1-X),
$$

where $\Delta F$ is the change in surface free energy, $N$ is the number of the crystal surface lattice sites, $k$ is the Boltzmann's constant, $T$ is the absolute temperature, and $X$ is fraction of surface sites occupied, respectively. $\alpha$ is the so-called Jackson roughing factor that is defined by Eq. [2]. As can be obtained from Eq. [1], for materials with $\alpha<2$, there is only one minimum value at 50 pct of surface site occupancy, indicating that the interface energetically prefers to be rough. On the other hand, in a material with $\alpha>3$, there are two energy minima at site occupancy 0 and 100 pct, suggesting that the interface will be smooth on the atomic scale $^{[2]}$ and the corresponding crystal turns out faceted in morphology.

$$
\alpha=\xi_{(\mathrm{hkl})} \frac{\Delta H_{\mathrm{m}}}{R T} .
$$

In Eq. [2], $\Delta H_{\mathrm{m}}$ is the enthalpy change for the crystal dissolution into melt bulk; $R$ is the ideal gas constant; and $\xi_{(\mathrm{hkl})}$ is the orientation factor, defined as the ratio between nearest sites for a growth unit in the surface of a crystal and the coordination number. It should be 

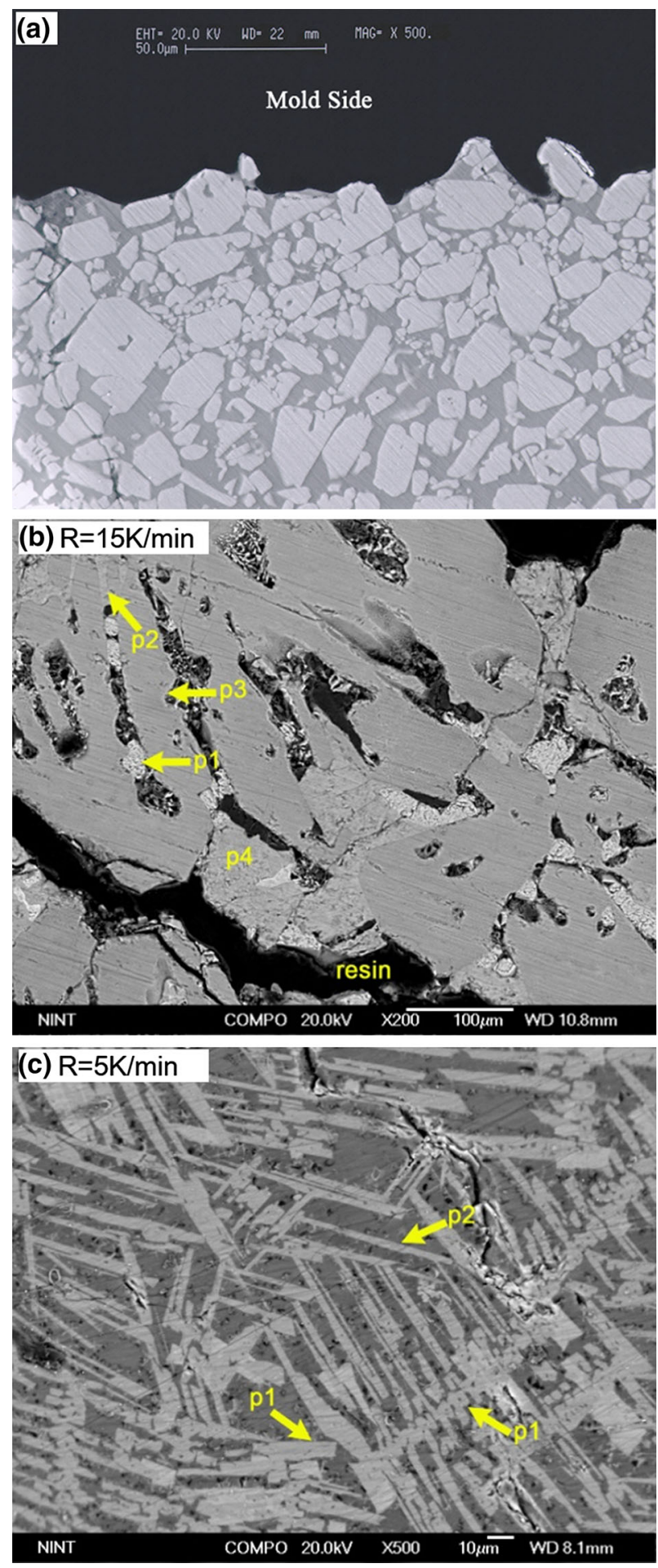

Fig. 1-Morphologies of crystals in lime-silica-based (a) and lime-alumina-based $(b)(c)$ mold fluxes, where P1, P2, and P3 in (b) represent $\mathrm{CaF} 2, \mathrm{Ca}_{3} \mathrm{Si}_{2} \mathrm{O}_{7}$, and $\mathrm{CaAl}_{4} \mathrm{O}_{7}$, respectively, and $\mathrm{P} 1$ and $\mathrm{P} 2$ in (c) denote $\mathrm{Ca}_{4} \mathrm{Si}_{2} \mathrm{~F}_{2} \mathrm{O}_{7}$ and $\mathrm{Ca}_{3} \mathrm{~B}_{2} \mathrm{O}_{6}$, respectively. (Reprinted from Metall. Mater. Trans. B, 2014, vol. 45B, pp. 1081-1097).

pointed out that it is not easy to obtain the orientation factor $\xi_{(\mathrm{hkl})}$ since structural parameters of many crystals, in particular for complicated crystals, are not completely confirmed yet. $\xi_{(\mathrm{hkl})}$ is generally considered as a constant for a specific crystalline, ${ }^{[21,22]}$ and the value of $\xi_{(\mathrm{hkl})}$ is less than unity, i.e., 1 , and greater or equal to $0.5 .^{[30]}$ Therefore, $\frac{\Delta H_{\mathrm{m}}}{R T}$ is the more critical part of Jackson $\alpha$ factor to characterize the morphology of crystals. In the present manuscript, $\xi_{(\mathrm{hkl})}$ is considered as 1 for a simplification in the same manner as done by other authors. ${ }^{[26]}$ In this case, how to calculate the enthalpy of dissolution $\Delta H_{\mathrm{m}}$ is the key point to obtain the Jackson $\alpha$ factor as a crystal morphology criterion, which will be introduced in the following part in detail.

Jackson proposed $\alpha$ factor to evaluate the crystal morphology only on the basis of a thermodynamic equilibrium system. In the non-equilibrium melt, the driving force, such as the thermal supercooling or constitutional supercooling, also affects the crystalline morphology, which is the so-called kinetic roughening. ${ }^{[23,24]}$ The driving force for a crystal nucleation and growth to take place is the degree of departure from the equilibrium state. In melt crystallization, the driving force can be evaluated as the difference between the equilibrium melting point $T_{m}$ and growth temperatures $T:^{[31]}$

$$
\Delta \mathrm{T}=T_{\mathrm{m}}-T \text { (supercooling). }
$$

To compare the supercooling among different melts, the supercooling degree is also used in the present article, defined as $\Delta \mathrm{T} / \mathrm{T}_{\mathrm{m}}$.

\section{CALCULATION OF ENTHALPY FOR DISSOLUTION}

A methodology was proposed to calculate the enthalpy for a crystal dissolution in a binary regular solution in References 21 and 22. The calculation of the enthalpy of dissolution can be demonstrated as the sum of "enthalpy" or "heats" involved in the following steps:

a. Separating the components of the solid compound phase, the heat absorption equals the decomposed enthalpy of the compound $\left(-\Delta H_{\mathrm{f}}\right.$, negative formation enthalpy),

$$
\begin{gathered}
A_{\mathrm{p}} B_{\mathrm{q}}(s)=p A(s)+q B(s) \\
\Delta H_{1}=-\Delta H_{\mathrm{f}} .
\end{gathered}
$$

b. Melting the solid components separately, the heat change is the sum of fusion enthalpy of pure component $\mathrm{A}\left(L_{\mathrm{A}}\right)$ and $\mathrm{B}\left(L_{\mathrm{B}}\right)$ :

$$
p A(s)=p A(1), q B(s)=q B(l)
$$

$$
\Delta H_{2}=p L_{\mathrm{A}}+q L_{\mathrm{B}}
$$


The fusion enthalpy of pure component A and B at different temperatures can be calculated by Eqs. [8] and [9], respectively.

$$
\begin{aligned}
& L_{\mathrm{A}}=L_{\mathrm{m}}^{\mathrm{A}}-\int_{T}^{T_{\mathrm{m}}^{\mathrm{A}}}\left(c_{p}^{l A}-c_{p}^{s A}\right) \mathrm{d} T \\
& L_{\mathrm{B}}=L_{\mathrm{m}}^{\mathrm{B}}-\int_{T}^{T_{\mathrm{m}}^{\mathrm{B}}}\left(c_{p}^{l B}-c_{p}^{s B}\right) \mathrm{d} T,
\end{aligned}
$$

where $L_{\mathrm{m}}^{\mathrm{A}}$ and $L_{\mathrm{m}}^{\mathrm{B}}$ are the fusion enthalpy of the pure component at the equilibrium melting temperature, i.e., $T_{\mathrm{m}}^{\mathrm{A}}$ and $T_{\mathrm{m}}^{\mathrm{B}}$, respectively. $c_{\mathrm{p}}^{\mathrm{li}}$ and $c_{\mathrm{p}}^{\mathrm{si}}$ denote the heat capacity of liquid and solid phase, respectively.

c. Mixing the liquid components into a large bath of liquid with the appropriate liquidus composition, the mixing process can be expressed as Eqs. [10] and [11] for binary melts and for multi-component melts, respectively. This part of heat change is the mixing enthalpy, i.e., the sum of the partial molar heats of solution of components $\mathrm{A}\left(H_{i, \mathrm{~A}}\right)$ and $\mathrm{B}\left(H_{i, B}\right)$ :

$$
\begin{gathered}
p A(1)+q B(1)=A_{\mathrm{p}} B_{\mathrm{q}(\text { melt })} \\
p A(1)+q B(l)=\left(p A_{(l)}+q B_{(l)}\right)_{\text {melt }} \\
\Delta H_{3}=p H_{i, \mathrm{~A}}+q H_{i, \mathrm{~B}} .
\end{gathered}
$$

The total heat of dissolution is as

$$
\Delta H_{\mathrm{m}, T}=\Delta H_{1}+\Delta H_{2}+\Delta H_{3} .
$$

In order to evaluate the enthalpy of dissolution by this method, all the thermodynamic parameters for the foregoing reactions should be obtained, but it is indeed not an easy task as some of them are not available, in particular in the multi-component solution. For example, the mixture enthalpy, i.e., $\Delta H_{3}$, for the multi-component solution is usually not available in the public literature.

In the present manuscript, a more convenient methodology was established to evaluate the enthalpy of dissolution in multi-component mold flux by applying the thermodynamic database FactSage 6.4. ${ }^{[32]}$ Generally, the Gibbs energy of formation $(\Delta G)$ for a compound or a crystal precipitating from a melt, Eq. [14], is expressed as Eq. [15]. In fact, Eq. [14] is just the reverse reaction of an universal formalism if one sums up Eqs. [4], [6], and [11], i.e., the dissolved reaction.

$$
\begin{gathered}
\left(a A_{(l)}+b B_{(l)}+\cdots+n N_{(l)}\right)_{\text {melt }}=A_{\mathrm{a}} B_{\mathrm{b}} \cdots N_{\mathrm{n}(\mathrm{s})} \\
\Delta G=\Delta G^{\theta}+R T \ln \left(\frac{1}{\alpha_{\mathrm{A}}^{\mathrm{a}} \alpha_{\mathrm{B}}^{\mathrm{b}} \cdots \alpha_{\mathrm{N}}^{\mathrm{n}}}\right)
\end{gathered}
$$

where $\Delta G^{\theta}$ is the standard Gibbs energy and $\alpha_{j}$ is the activity of component $\boldsymbol{j}$ in the melts related to pure liquid. The enthalpy of precipitate formation, $\Delta H$, is then calculated using the Gibbs-Helmholtz equation, ${ }^{[33]}$

$$
\left(\frac{\partial\left(\frac{G}{T}\right)}{\partial T}\right)=\frac{\Delta H}{T^{2}} .
$$

The enthalpy of dissolution for the Jackson $\alpha$ factor evaluation can be obtained as

$$
\Delta H_{\mathrm{m}}=-\Delta H .
$$

During the present calculation, the standard Gibbs energy $\Delta G^{\theta}$ was calculated in the FactSage "Reaction" module by setting up a reaction similar to Eq. [14]. The activities of various components in the mold flux were then calculated using the "Equilib" module. A temperature step of $10 \mathrm{~K}\left(10^{\circ} \mathrm{C}\right)$ was applied during the present calculation.

\section{EXPERIMENTAL}

DSC measurements were carried out both on lime-silica-based and lime-alumina-based mold fluxes. The chemical compositions of the mold fluxes are presented in Table I. Mold New 2 to New 6 are lime-alumina-based mold fluxes with different $\mathrm{CaO}$ / $\mathrm{Al}_{2} \mathrm{O}_{3}$ and $\mathrm{B}_{2} \mathrm{O}_{3}$ contents. Slag B-D are the lime-silica-based mold flux with different basicities, and Slag B-1 is the comparison to Slag B by addition of 1.8 mass pet $\mathrm{Li}_{2} \mathrm{O}$. The crystallization behaviors of mold fluxes were investigated by DSC (Netzsch STA 449C; Netzsch Instrument Inc., Germany). Pure $a-\mathrm{Al}_{2} \mathrm{O}_{3}$ powder was used as reference material in DSC measurement. The mold flux samples were ground into powder before DSC measurements. The DSC measurement was performed at different cooling rates $(5,10,15,20$, and $25 \mathrm{~K} / \mathrm{min})$ in $\mathrm{Ar}$ atmosphere at a flow rate of $60 \mathrm{~mL} / \mathrm{min}$. About $60 \mathrm{mg}$ of sample powder was heated at a constant heating rate of $20 \mathrm{~K} /$ min from room temperature to $1573 \mathrm{~K}\left(1300{ }^{\circ} \mathrm{C}\right)$ in a platinum crucible with a diameter of $5 \mathrm{~mm}$ and a height of $5 \mathrm{~mm}$, and then held for 3 minutes to homogenize its chemical composition. Subsequently, the liquid sample was cooled at a constant cooling rate to room temperature. In addition, the iso-thermal DSC experiments for the lime-silica-based Slag B and $\mathrm{D}$ were also carried out at four different temperatures for a comparison. The microstructure and crystal compositions of mold flux samples after DSC measurement were determined by FE-SEM/EDS (JSM$7401 \mathrm{~F}$, JEOL, Japan). In addition, a series of noniso-thermal treatment experiments in an induction furnace were carried out in order to identify the crystalline phases by XRD analyzer, since the mass of mold flux samples after DSC experiments are too small to determine crystalline phase by XRD. Table II shows the crystalline phases of mold fluxes identified by XRD analysis. More detailed procedures can be seen in References 13 through 15. 
Table I. Chemical Composition of the Mold Fluxes, Mass Pct

\begin{tabular}{|c|c|c|c|c|c|c|c|c|}
\hline No & $\mathrm{CaO}$ & $\mathrm{SiO}_{2}$ & $\mathrm{Al}_{2} \mathrm{O}_{3}$ & $\mathrm{Na}_{2} \mathrm{O}$ & $F$ & $\mathrm{MgO}$ & $\mathrm{Li}_{2} \mathrm{O}$ & $\mathrm{B}_{2} \mathrm{O}_{3}$ \\
\hline New2 & 30.7 & 2.2 & 25.2 & 12.3 & 15.1 & & 3.1 & 5.4 \\
\hline New3 & 32.0 & 2.3 & 26.2 & 7.4 & 13.9 & & 6.4 & \\
\hline New4 & 37.9 & 9.0 & 11.4 & 9 & 8.9 & & 4.9 & 16.0 \\
\hline New5 & 42.6 & 11.9 & 13 & 4.8 & 9.3 & & 4.9 & 10.8 \\
\hline New6 & 37.8 & 8.9 & 11.5 & 1.0 & 8.1 & & 6.2 & 10.0 \\
\hline B & 38.5 & 41.1 & 5.0 & 7.3 & 7 & 0.8 & - & - \\
\hline B-1 & 37.5 & 39.3 & 5.1 & 7.5 & 7.4 & 0.7 & 1.8 & - \\
\hline $\mathrm{C}$ & 41.7 & 36.7 & 5.3 & 7.4 & 7.2 & 0.8 & - & - \\
\hline $\mathrm{D}$ & 44.8 & 33.4 & 5.4 & 7.6 & 7.6 & 0.8 & - & - \\
\hline
\end{tabular}

Table II. XRD Analysis Results of Crystalline Phase in the Mold Fluxes Quenched at the Desired Target Temperatures

\begin{tabular}{|c|c|c|}
\hline Sample No. & Target Temperature $\left[\mathrm{K}\left({ }^{\circ} \mathrm{C}\right)\right]$ & Crystalline Phase Identified by XRD \\
\hline \multirow[t]{3}{*}{ New2 } & $1033(760)$ & $\mathrm{CaF}_{2}$ \\
\hline & $938(665)$ & $\mathrm{CaF}_{2}+\mathrm{CaO} \cdot 2 \mathrm{Al}_{2} \mathrm{O}_{3}$ \\
\hline & $873(600)$ & $\mathrm{CaF}_{2}+\mathrm{CaO} \cdot 2 \mathrm{Al}_{2} \mathrm{O}_{3}+2 \mathrm{CaO} \cdot \mathrm{B}_{2} \mathrm{O}_{3}$ \\
\hline \multirow[t]{3}{*}{ New3 } & $1470(1197)$ & unidentified \\
\hline & $1173(900)$ & $\mathrm{CaF}_{2}+3 \mathrm{CaO} \cdot 2 \mathrm{SiO}_{2}$ \\
\hline & $673(400)$ & $\mathrm{CaF}_{2}+3 \mathrm{CaO} \cdot 2 \mathrm{SiO}_{2}+3 \mathrm{CaO} \cdot \mathrm{Al}_{2} \mathrm{O}_{3}$ \\
\hline \multirow[t]{2}{*}{ New4 } & $923(650)$ & Cuspidine \\
\hline & $788(515)$ & Cuspidine $+9 \mathrm{CaO} \cdot 3 \mathrm{~B}_{2} \mathrm{O}_{3} \cdot \mathrm{CaF} 2$ \\
\hline \multirow[t]{2}{*}{ New5 } & $923(650)$ & Cuspidine \\
\hline & $793(520)$ & Cuspidine $+\mathrm{CaO} \cdot \mathrm{B}_{2} \mathrm{O}_{3}$ \\
\hline \multirow[t]{2}{*}{ New6 } & $923(650)$ & Cuspidine \\
\hline & $673(400)$ & Cuspidine $+\mathrm{CaO} \cdot \mathrm{B}_{2} \mathrm{O}_{3}$ \\
\hline \multirow[t]{2}{*}{ B } & $1431(1158)$ & Cuspidine \\
\hline & $1355(1082)$ & Cuspidine + Wollastonite \\
\hline B-1 & $1392(1119)$ & Cuspidine \\
\hline $\mathrm{C}$ & $1496(1223)$ & Cuspidine \\
\hline \multirow[t]{2}{*}{$\mathrm{D}$} & $1518(1245)$ & Cuspidine \\
\hline & $1204(931)$ & Cuspidine \\
\hline
\end{tabular}

\section{RESULTS AND DISCUSSIONS}

\section{A. Jackson $\alpha$ Factor of Typical Crystals in Mold Fluxes}

The fusion enthalpy at the melting point of some typical crystals and their corresponding Jackson $\alpha$ factors are calculated. The results are as shown in Table III, in which the asterisked data are cited from a well-known public database ${ }^{[32,33]}$ for a comparison. It can be seen that the calculated results by applying FactSage are very close to those picked up from the thermodynamic database, ${ }^{[34,35]}$ suggesting that the present method can achieve a reasonable evaluation of enthalpy for crystal dissolution and Jackson $\alpha$ factor. For many binary crystals, in particular ternary and higher order system ones, there are no available thermodynamic data in public literature, and thus, the application of commercial thermodynamic databases, such as FactSage, is the only way to obtain the relative reasonable estimation. It can be seen that different crystals have varying Jackson $\alpha$ factors that suggest they should have different morphologies and anisotropic degrees.

\section{B. Crystal Morphology in Lime-Alumina-Based Mold Fluxes}

Figure 2 shows the typical crystal morphology of the lime-alumina-based mold fluxes New2 after DSC measurement at different cooling rates. It is confirmed by FE-SEM/EDS and XRD that there are three kinds of crystalline phases in each sample, shown as in Table II, and they show distinctly different morphologies. Firstly, a large amount of fine granuliform-shaped $\mathrm{CaF}_{2}$ crystals with smooth surface, which are marked as $\mathrm{P} 1$ in the figures, are found in each sample, and some of them possessed a dendritic shape. The second-phase crystalline is confirmed as $\mathrm{CaAl}_{4} \mathrm{O}_{7}$, which takes up the largest crystalline fraction in this kind of mold flux and are marked as P2, and they appear to have coarse blocky shape. Another type of crystalline phase marked as P3 is needle-like shape and it is verified as calcium borates in composition. It should be pointed out that calcium aluminate crystals $\left(\mathrm{CA}_{2}\right.$ and $\left.\mathrm{C}_{3} \mathrm{~A}\right)$ are the dominant phases in the lime-alumina-based mold fluxes with low or no $\mathrm{B}_{2} \mathrm{O}_{3}$ content, such as in slag New 2 and New 3, and they appear as a blocky shape usually. In addition, the calcium borate crystals $\left(\mathrm{Ca}_{3} \mathrm{~B}_{2} \mathrm{O}_{6}, \mathrm{Ca}_{2} \mathrm{~B}_{2} \mathrm{O}_{5}\right.$, $\mathrm{CaB}_{2} \mathrm{O}_{4}$, and $\mathrm{Ca}_{9} \mathrm{~B}_{6} \mathrm{~F}_{2} \mathrm{O}_{17}$ ), which are mainly needle-like in morphology, are the primary crystals in the $\mathrm{B}_{2} \mathrm{O}_{3}$-rich lime-alumina-based mold fluxes, such as in slag New 4, 5, and 6. More detailed composition and morphology information can be checked in Reference 15.

Figure 3 shows the relations between Jackson $\alpha$ factor and supercooling for the three types of typical crystals in slag New 2. The supercooling are estimated by 
Table III. The Jackson $\alpha$ Factors of Some Typical Crystals in Mold Fluxes

\begin{tabular}{lccc}
\hline Crystal & Melting Point $\left[\mathrm{K}\left({ }^{\circ} \mathrm{C}\right)\right]$ & Latent Heat $(\mathrm{kJ} / \mathrm{mol})$ & $\alpha$ Factor \\
\hline $\mathrm{CaO}$ (lime) & $2845(2572) / 2888^{*}$ & $28.50 / 28.45^{*}$ & $3.36 / 3.31^{*}$ \\
$\mathrm{Al}_{2} \mathrm{O}_{3}$ (corundum) & $2327(2054) / 2327^{*}$ & $118.41 / 118.41^{*}$ & $6.12 / 6.12^{*}$ \\
$\mathrm{SiO}_{2}$ (cristobalite) & $1996(1723) / 1996^{*}$ & $9.58 / 9.58^{*}$ & $0.58 / 0.58^{*}$ \\
$\mathrm{CaF}_{2}$ & $1691(1418) / 1691^{*}$ & $29.71 / 29.71^{*}$ & $2.11 / 2.11^{*}$ \\
$\mathrm{CaSiO}_{3}$ (wollastonite) & $1813(1540) / 1817^{*}$ & $57.00 / 56.07^{*}$ & $3.7 / 3.71^{*}$ \\
$\mathrm{Ca}_{3} \mathrm{~B}_{2} \mathrm{O}_{6}$ & $1750(1477) / 1763^{*}$ & $150.50 / 148.53^{*}$ & $10.33 / 10.13^{*}$ \\
$\mathrm{CaAl}_{4} \mathrm{O}_{7}$ & $2038(1765)$ & 55.0 & 7.57 \\
$\mathrm{CaAl}_{2} \mathrm{O}_{4}$ & $1877(1604)$ & 432.0 & 3.51 \\
$\mathrm{Ca}_{12} \mathrm{Al}_{14} \mathrm{O}_{33}$ & 72.0 & 30.38 \\
$\mathrm{Ca}_{3} \mathrm{Al}_{2} \mathrm{O}_{6}$ & $1709(1433)$ & 156.1 & 11.18 \\
$\mathrm{Ca}_{4} \mathrm{Si}_{2} \mathrm{~F}_{2} \mathrm{O}_{7}$ & 575 & 11.19 \\
$\mathrm{Ca}_{12} \mathrm{Al}_{14} \mathrm{~F}_{2} \mathrm{O}_{32}$ & $1814(1541)$ & 130 & 37.4 \\
$\mathrm{Ca}_{4} \mathrm{Al}_{6} \mathrm{~F}_{2} \mathrm{O}_{12}$ & $1677(1404)$ & & 8.77 \\
\hline
\end{tabular}

comparing the crystallization temperature and the equilibrium melting temperature calculated by FactSage. $\mathrm{Ca}_{3} \mathrm{~B}_{2} \mathrm{O}_{6}$ is chosen as the representative of calcium borate crystals since it has strongest tendency to precipitate on the basis of thermodynamic calculation by FactSage. It can be seen that the three types of crystals have very different Jackson $\alpha$ factors: they are between 3.7 and 4.5 for $\mathrm{CaF}_{2}$, between 9.4 and 9.8 for $\mathrm{CaAl}_{4} \mathrm{O}_{7}$, and between 10.6 and 11.2 for $\mathrm{Ca}_{3} \mathrm{~B}_{2} \mathrm{O}_{6}$, respectively. According to Jackson's theory, ${ }^{[1,18]}$ the crystal is faceted in morphology when the $\alpha$ factor is larger than the critical value and its anisotropy increases with the $\alpha$ factor increase. The three types of crystals in Figure 2 are mainly faceted in morphology and, obviously, the anisotropy increases from $\mathrm{CaF}_{2}$ (fine granuliform), $\mathrm{CaAl}_{4} \mathrm{O}_{7}$ (blocky) to $\mathrm{Ca}_{3} \mathrm{~B}_{2} \mathrm{O}_{6}$ (needle-like). The experimental observations are in good agreement with theoretical prediction. So it well explains why the three types of crystals show different morphologies. Also, it is clear that the morphology of $\mathrm{CaAl}_{4} \mathrm{O}_{7}$ crystals changes from large block with clear angularities to the smaller ones by increasing the cooling rate, and some $\mathrm{CaF}_{2}$ crystals appear with dendritic morphology which means that superccooling also plays a role on the crystal morphology.

\section{Cuspidine Morphology in Lime-Silica-Based Mold Fluxes}

Since cuspidine crystal in lime-silica-based mold flux has been verified a relative favorable lubrication performance during high-Al AHSS steel CC process, and thus, it is necessary to understand cuspidine morphology evolution behaviors in lime-silica-based mold fluxes for the purpose of crystal morphology modification in lime-alumina-based mold fluxes.

The dominant crystalline of lime-silica-based Slag B, B-1, C, and D are all confirmed as cuspidine identified by XRD analysis as shown in Table II. ${ }^{[13,14]}$ Figure 4 shows the morphology of cuspidine crystal after iso-thermal DSC measurement at different crystallization temperatures for Slag B and D, and Table IV lists their supercooling, Jackson $\alpha$ factor, and corresponding crystal morphology. It should be pointed out that only cuspidine is present at the iso-thermal experimental temperatures since the second phase, i.e., wollastonite, precipitates at very low temperature for slag B according to the XRD identified results as shown in Table II. As shown in Figures 4(a) and (b), the crystal morphology of Slag B are dendritic and the dendritic structures are more developed with crystallization temperature decrease. In addition, the crystal morphology of Slag $\mathrm{D}$ is mostly faceted as shown in Figures 4(c) and (d), while there is also a dendritic tendency at the lower crystallization temperature in Figure 4(d). As can be seen from Table IV that cuspidine of melt crystallization in slag B and D have a very similar Jackson $\alpha$ factor, but the undercooling for crystallization of slag B is much greater than that of slag $\mathrm{D}$. Therefore, it can be concluded that the crystal morphology difference between Slag B and Slag D is mainly due to the supercooling difference rather than Jackson $\alpha$ factor.

Figure 5 shows the crystal morphology of four kinds of lime-silica-based mold fluxes after DSC measurement with continuous cooling at a rate of $20 \mathrm{~K} / \mathrm{min}$, and Table $\mathrm{V}$ lists the supercooling and the Jackson $\alpha$ factors correspondingly. It can be seen from the figure and table that the crystal morphology evolved from facets to dendritic shape by increasing supercooling of crystallization that are in agreement with the foregoing iso-thermal DSC experimental results. Also, their Jackson $\alpha$ factors are very close to each other and much larger than the critical value. It suggests once more that the supercooling or supercooling degree also considerably affects the crystal morphology. Additionally, the composition of Slag B-1 is very similar to that of slag B except for 1.8 mass pet addition of $\mathrm{Li}_{2} \mathrm{O}$, while its supercooling for cuspidine crystallization is obviously lower than that of slag B, which gives rise to its crystal morphology much more faceted and less dendritic. This indicates that the slag composition, such as the $\mathrm{Li}_{2} \mathrm{O}$ content, can also influence the crystal morphology by changing the mold flux properties.

Figure 6 shows the calculated Jackson $\alpha$ factors for cuspidine in the four types of lime-silica-based mold 

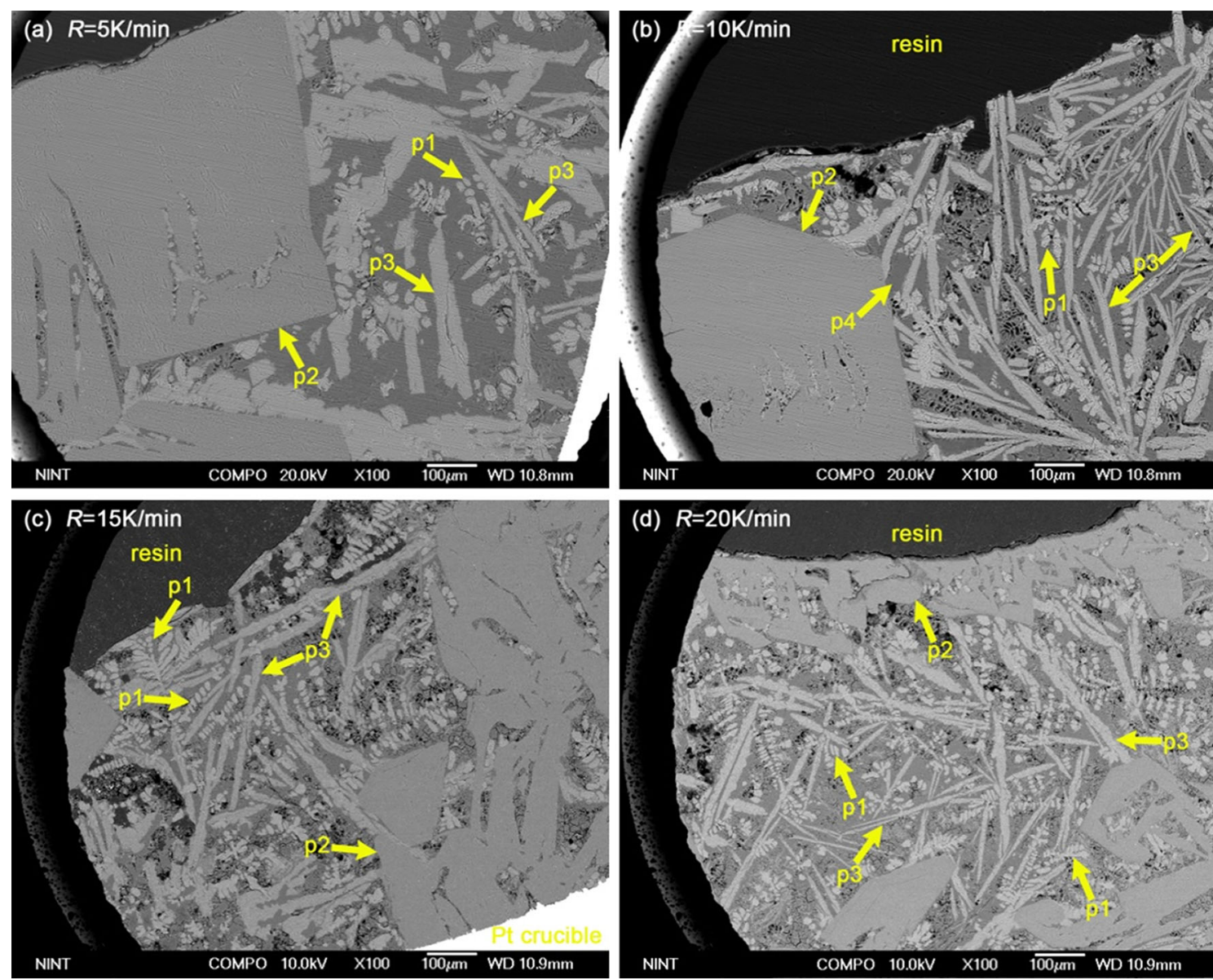

Fig. 2-Morphology of crystals variation for Slag NEW 2 at different cooling rates. (Reprinted from Metall. Mater. Trans. B, 2014, vol. 45B, pp. 1081-1097)

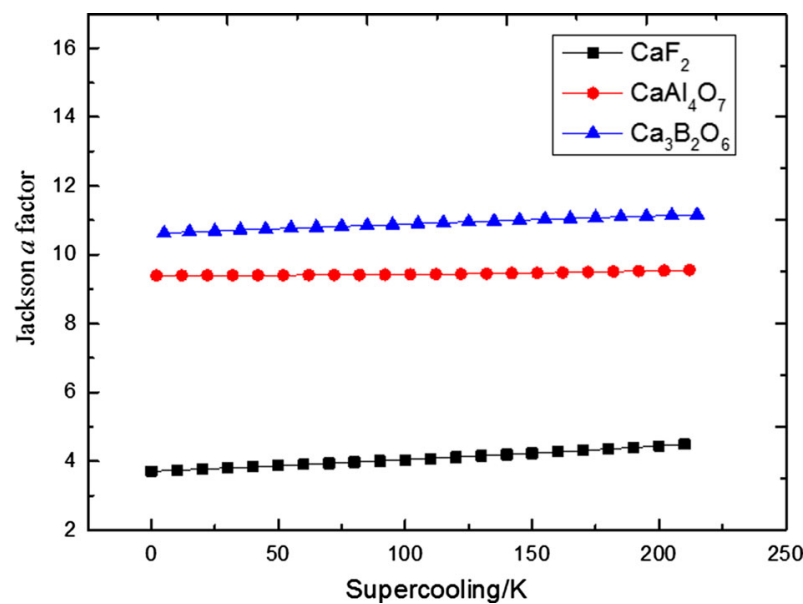

Fig. 3-Jackson $\alpha$ factor $v s$ undercooling of three typical types of crystals for Slag New 2 during cooling process.

fluxes including the pure cuspidine melt, i.e., with the same stoichiometric composition as cuspidine. It can be seen that the Jackson $\alpha$ factor of cuspidine crystal increases slightly with the decrease in mold flux basicity compared to those of Slag B, C, and D and increases with the addition of a small amount of $\mathrm{Li}_{2} \mathrm{O}$ compared to those of Slag B-1 and B. In addition, it increases with the supercooling increase.

\section{Effect of Supercooling Degree on Crystal Morphology}

Figure 7 shows the supercooling degree and their corresponding Jackson $\alpha$ factors for the cuspidine crystallization in the four kinds of lime-silica-based mold fluxes, where the $y$ axis is drawn as the degree of supercooling degree $\left(\Delta \mathrm{T} / \mathrm{T}_{\mathrm{m}}\right)$ for a more fair comparison. Similar to Temkin's ${ }^{[23,24]}$ conclusion, a critical line for cuspidine crystal kinetic roughening can be evaluated as well, shown as the dot line in the figure. When the supercooling is lower than the critical line (Region A), the cuspidine morphology is faceted, whereas the crystal morphology appears with dendritic shape when the supercooling over the critical value (Region B) as the kinetic roughening occurs. For the cuspidine precipitation from these lime-silica-based mold fluxes, the critical degree of supercooling is estimated between 0.05 and 0.06 and increases with the Jackson $\alpha$ factor.

From Figures 6 and 7, one observes that the supercooling has complicated effects on the cuspidine morphology: by increasing supercooling within the critical line region, it will increase the Jackson $\alpha$ factor and, thus, enhance 

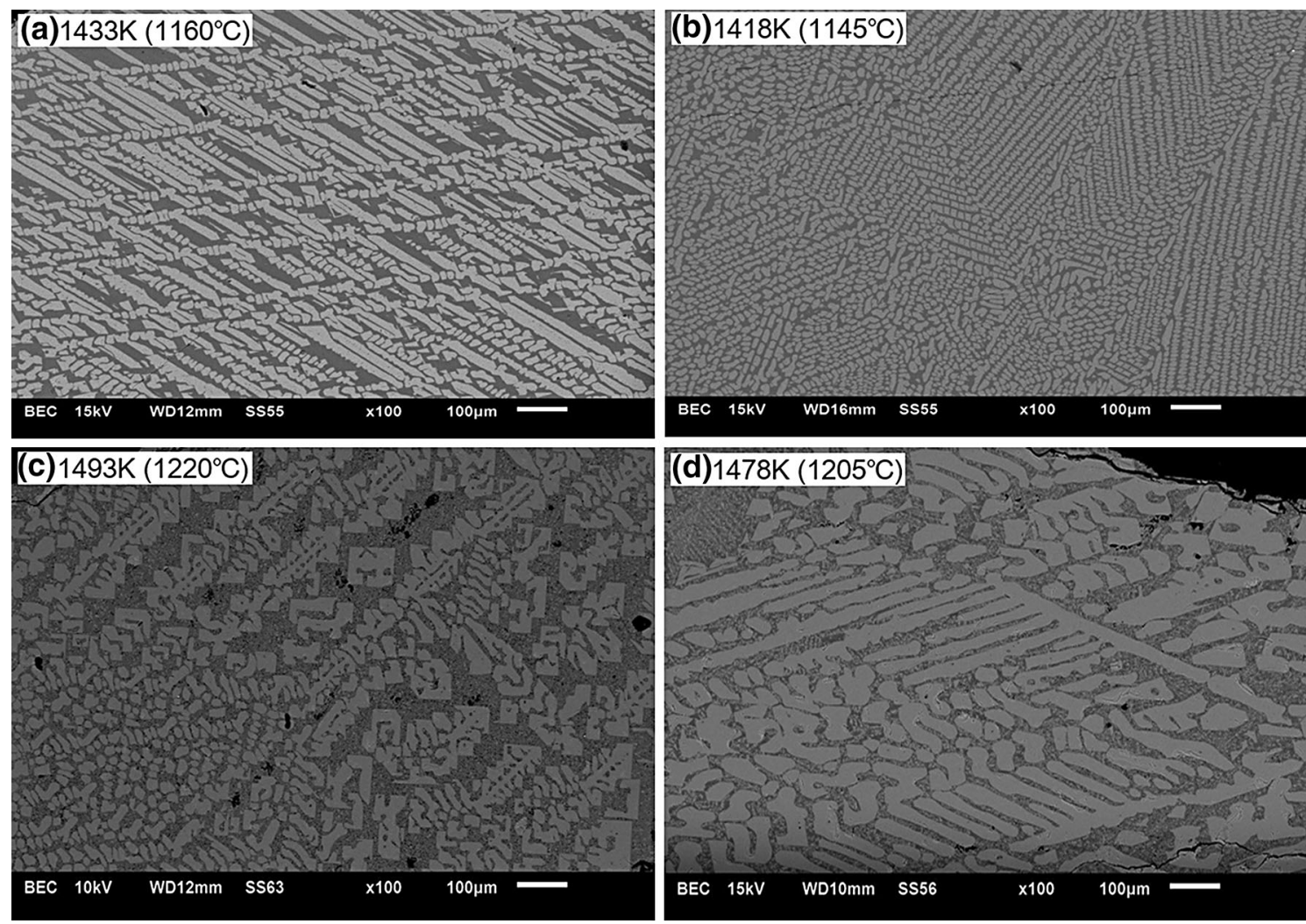

Fig. 4 - Cuspidine morphology in Slag B, $(a)$ and $(b)$, and Slag D, $(c)$ and $(d)$, after iso-thermal DSC measurement at the different crystallization temperatures. (Reprinted from Metall. Mater. Trans. B, 2015, vol. 46B, pp. 2374-2383).

Table IV. Undercooling, Jackson $\alpha$ Factor, and Morphology of Crystal in Slag B and D in Fig. 4

\begin{tabular}{|c|c|c|c|c|}
\hline No. & a (slagB) & b (slagB) & c (slagD) & $\mathrm{d}(\operatorname{slag} \mathrm{D})$ \\
\hline$\Delta \mathrm{T}\left[\mathrm{K}\left({ }^{\circ} \mathrm{C}\right)\right]$ & $88[88]$ & $103[103]$ & $53[53]$ & $68[68]$ \\
\hline$\Delta \mathrm{T} / \mathrm{T}_{\mathrm{m}}$ & 0.058 & 0.068 & 0.034 & 0.044 \\
\hline$\alpha$ factor & 13.52 & 13.65 & 12.68 & 12.57 \\
\hline Crystal morphology & dendritic & dendritic & faceted & faceted \\
\hline
\end{tabular}

Table V. Undercooling, Jackson $\alpha$ Factor, and Morphology of Crystal in Four Lime-Silica-Based Mold Flux at a Cooling Rate of $20 \mathrm{~K} / \mathrm{min}$ in Fig. 5

\begin{tabular}{|c|c|c|c|c|}
\hline No. & a (slagB) & b (slagB-1) & c (slagC) & $\mathrm{d}($ slag D) \\
\hline$\Delta \mathrm{T}\left[\mathrm{K}\left(\left({ }^{\circ} \mathrm{C}\right)\right]\right.$ & $101[101]$ & $86[86]$ & $45[45]$ & $40[40]$ \\
\hline$\Delta \mathrm{T} / \mathrm{T}_{\mathrm{m}}$ & 0.066 & 0.058 & 0.029 & 0.031 \\
\hline$\alpha$ factor & 13.64 & 13.88 & 12.80 & 12.48 \\
\hline Crystal morphology & dendritic & faceted & faceted & faceted \\
\hline
\end{tabular}

faceted cuspidine precipitation, while supercooling over the critical value, kinetic roughening takes place and it is likely to precipitate dendritic cuspidine. The supercooling for crystallization of the slag B is remarkably larger than that of slag D, and thus, crystal in the slag B is more likely to be dendritic as shown in Figure 4. Interestingly, the present findings are in quite good agreement with $\mathrm{Lu}$ et al. ${ }^{[23]}$ and Heulens ${ }^{\text {,[26] }}$ experimental results regarding the alpha-Ni crystal and wollastonite morphology evolution under different supercooling degrees.
By combining the present results with those of Temkin, it can be concluded that the crystal with higher Jackson $\alpha$ factor is more difficult to form dendritic structure as greater critical supercooling degree is usually needed. Also, it shows the similar tendency in lime-alumina-based mold fluxes: some $\mathrm{CaF}_{2}$ crystals become dendritic under the relatively low supercooling $\left[<50 \mathrm{~K}\left(50^{\circ} \mathrm{C}\right)\right]$ due to their small Jackson $\alpha$ factor values, while the calcium aluminate and calcium borate crystals retain faceted morphology under relatively high 

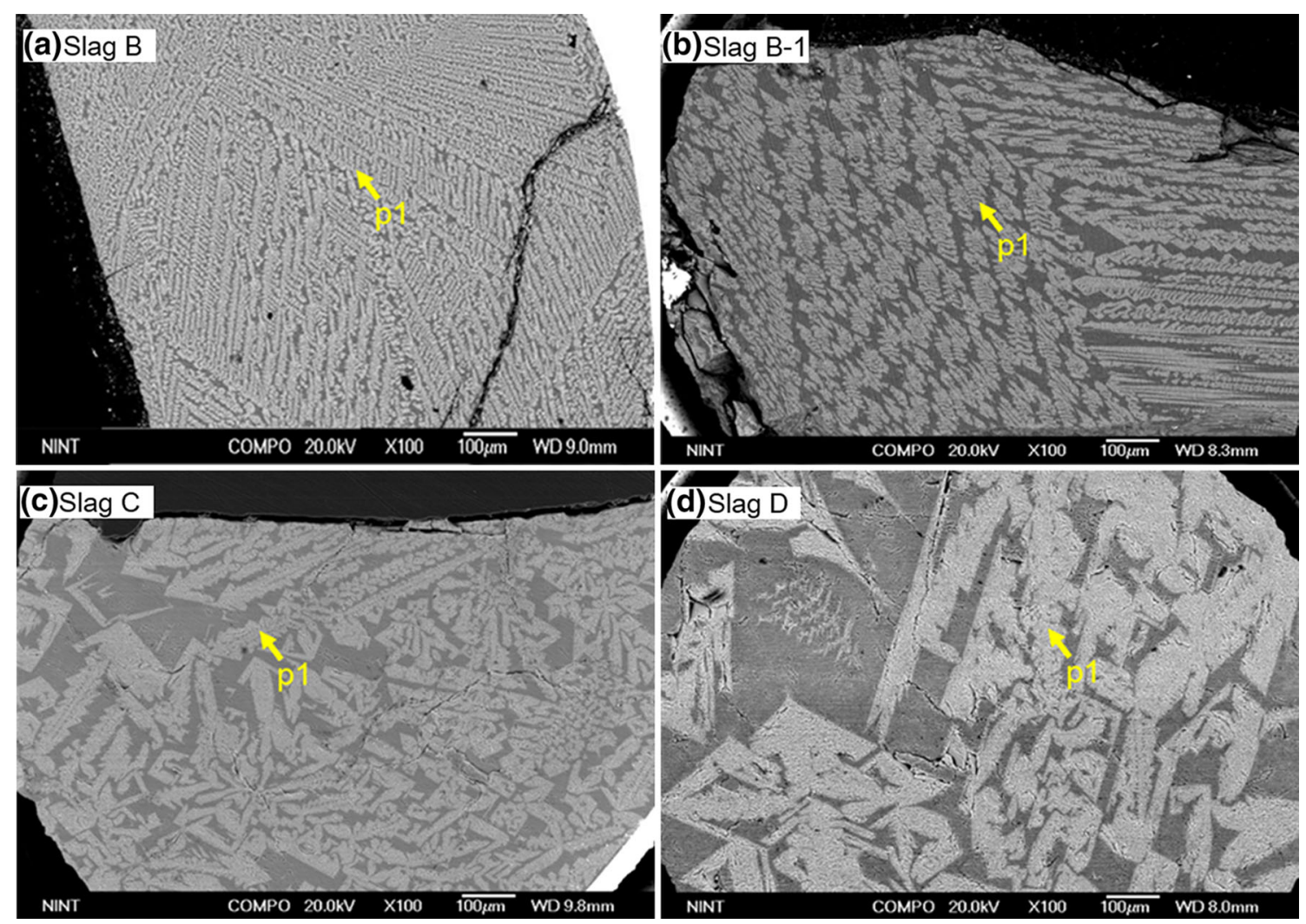

Fig. 5-The crystal morphology of lime-silica-based mold fluxes after DSC measurement at cooling rate of $20 \mathrm{~K} / \mathrm{min}$. (Reprinted from Metall. Mater. Trans. B, 2014, vol. 45B, pp. 1874-1886).

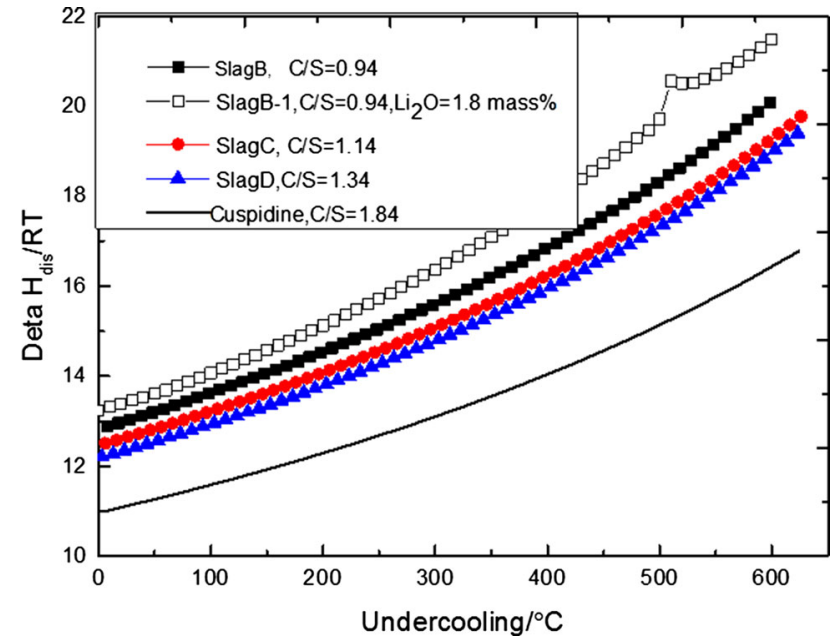

Fig. 6-Jackson $\alpha$ factor for cuspidine precipitation in four kinds of $\mathrm{CaO}-\mathrm{SiO}_{2}$-based mold fluxes under different supercooling degrees.

supercooling [100 $\mathrm{K}$ and $200 \mathrm{~K}\left(100^{\circ} \mathrm{C}\right.$ and $\left.\left.200{ }^{\circ} \mathrm{C}\right)\right]$ due to their relatively larger Jackson $\alpha$ factor.

Practically, one could control faceted or dendritic crystal morphology by matching the suitable Jackson $\alpha$ factor in the manner of the melt composition adjustment and heat treatment on the basis of the similar crystal morphology transition diagram like Figure 7; thus, these kinds of diagrams are very essential for crystal morphology control. The further work should be performed to obtain the similar diagrams for the crystals in lime-alumina-based mold fluxes.

As we know, crystallization is a complex process governed by nucleation and crystal growth. The crystal morphology is mostly determined by the crystal growth process after nucleation. ${ }^{[36]}$ Furthermore, the crystal growth could be generally divided into the following two steps: (1) the elements diffuse from the melt bulk to the crystal-melt interface; and (2) chemical reactions take place at the interface. The rate at which a crystal grows can be controlled by any of these two factors. If the crystal growth is controlled by the chemical reaction, the crystal morphology would be likely faceted in the case of its Jackson $\alpha$ factor larger than the critical value according to its derivation. The crystal morphology will tend to be dendritic if the growth is controlled by element diffusion process. ${ }^{[36]}$ The chemical reaction rate is proportional to the driving force, and the element diffusion rate is inverse proportional to the melt viscosity. ${ }^{[32,36]}$ Thus, it could infer that crystal morphology transition with the supercooling degree increase, i.e., kinetic roughness, is high possible due to the crystal growth controlling step changing from step 2, i.e., chemical reaction at the interface, to step 1, i.e., element diffusion to the interface since the melt viscosity would increase largely with the supercooling increase. 


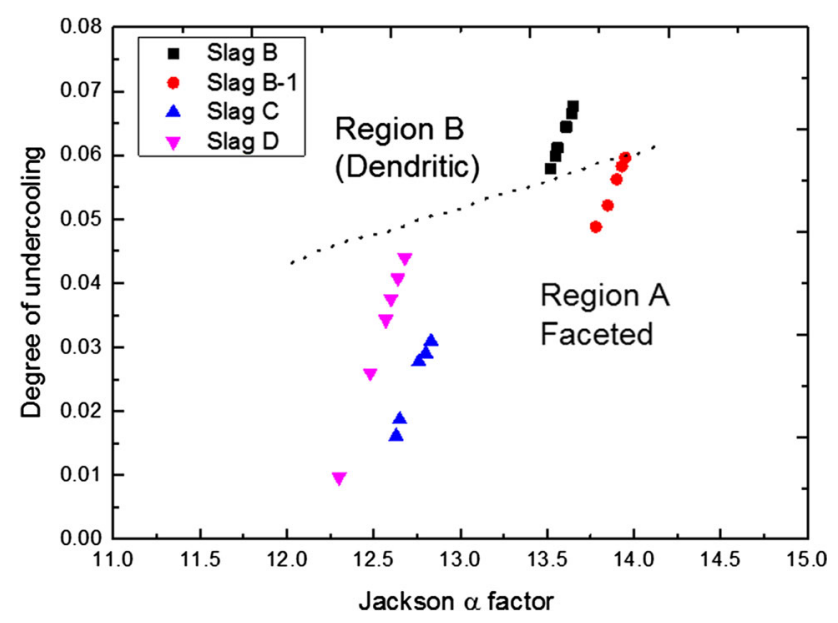

Fig. 7-Degree of undercooling and Jackson $\alpha$ factor dependence of cuspidine crystal morphology.

\section{E. Effect of Melt Composition on Crystal Morphology}

As shown in Figure 6, the melt composition could affect the Jackson $\alpha$ factor of crystal. The effects of melt composition on the crystal morphology is much more complicated since it also plays a role on other parameters including Jackson $\alpha$ factor, such as melting point, viscosity, supercooling degree of crystallization, and so on.

For slag B, C, and D, Jackson $\alpha$ factor for cuspidine crystal increases slightly with slag basicity decrease, but the supercooling of mold flux with lower basicity, such as slag B, is obviously larger than that of mold fluxes with higher basicity; thus, crystal in the slag B is more likely to be dendritic, as shown in Figures 4, 5, and 6. In addition, the driving forces, i.e., constitutional supercooling, for precipitating cuspidine in melt increase with the slag basicity decrease, and thus the corresponding Jackson $\alpha$ factor increases. On the other hand, our previous viscosity measurements have verified that the melt viscosity increases obviously with the basicity decrease for slag B, C, and D. ${ }^{[37]}$ Therefore, it suggests the cuspidine crystal growth in lower basicity mold flux, slag $\mathrm{B}$, is more likely to be controlled by the element diffusion, while that in the slag D is likely controlled by interface chemical reaction. This explains why cuspidine appears with different morphologies in the foregoing mold fluxes.

By comparing slag B and slag B-1, one can find that the addition of even a small amount of $\mathrm{Li}_{2} \mathrm{O}$ into the mold flux can not only increase the value of Jackson $\alpha$ factor for cuspidine crystal as shown in Figure 6 but also decrease the degree of supercooling of crystallization as shown in Figure 6; thus, it can improve the faceted cuspidine crystal precipitation from the lime-silica-based mold fluxes. In addition, it was confirmed by Kim et al. measurement that the melt viscosity decreased by adding a small amount of $\mathrm{Li}_{2} \mathrm{O}$ into mold flux. ${ }^{[12]}$ Also, experimental results of Liu et al. ${ }^{[38]}$ demonstrated that more faceted crystal precipitated by increasing $\mathrm{Li}_{2} \mathrm{O}$ content in mold fluxes within a reasonable amount, which is in accordance with our present findings.
In addition, it should be pointed out that the melt composition will change with crystallization process, and thus, the morphology of the second-phase crystal is probably somewhat different from the one in the mold flux of only first-phase crystal precipitation, since the Jackson $\alpha$ factor, supercooling, melt viscosity, and so on are perhaps different. Thus, the morphology control of the second- or third-phase crystal is much more difficult and further work should be performed.

In brief, it can be concluded that Jackson $\alpha$ factor and the supercooling of crystallization are the most significant parameters to determine the crystal morphology since mold flux composition affects the crystal morphology through changing these two factors. In order to control the faceted crystal morphology in the mold flux, the favorable Jackson $\alpha$ factor for the primary crystal should be selected firstly, and then the relative lower supercooling of crystallization should be taken into consideration. Many investigations ${ }^{[14,16,39-41]}$ have confirmed the supercooling of crystallization is related to the activation energy of crystallization. Our previous works have investigated their relations both in lime-silica-based ${ }^{[16,37]}$ and lime-alumina-based ${ }^{[14]}$ mold fluxes. Here, it would not be discussed in detail any more.

The present findings suggest that Jackson $\alpha$ factor and supercooling should be taken into account during the design of the lime-alumina-based mold flux for casting high-Al AHSS steel like other slag properties, such as melting point, viscosity, basicity, and so on. This kind of work has been carried out by the present authors and will be introduced soon.

\section{CONCLUSIONS}

In the present work, the attempts to control the crystal morphology are made for the purpose of lubrication improvement of lime-alumina-based mold flux for casing high-Al AHSS. The following conclusions can be obtained:

First, Jackson $\alpha$ factor was introduced to understand the crystal morphology control in a multi-component mold flux. In addition, the enthalpy of dissolution and the corresponding Jackson $\alpha$ factors for crystals of melt crystallization in multi-component mold flux were established and reasonably evaluated by applying the databases of FactSage.

Second, $\mathrm{CaF}_{2}$, calcium aluminate, calcium borate, and cuspidine precipitated in mold fluxes show different morphologies due to their different Jackson $\alpha$ factors, and the crystals tend to be more faceted and anisotropic with their Jackson $\alpha$ factor increase.

Third, there is a critical undercooling degree for crystal morphology dendritic transition. When the undercooling degrees locate within the critical value region, the corresponding crystals appear faceted in morphology. While the undercooling over the critical value, the crystals transform to be dendritic. In addition, the critical supercooling degrees for cuspidine dendritic transition in the lime-silica-based mold fluxes are evaluated to be between 0.05 and 0.06 . 
Finally, addition of a small amount of $\mathrm{Li}_{2} \mathrm{O}$ in the mold fluxes can increase the Jackson $\alpha$ factor of cuspidine crystal and decrease the supercooling for cuspidine precipitation, and thus, it is favorable to enhance a faceted cuspidine crystal.

\section{ACKNOWLEDGMENT}

We gratefully acknowledge the financial support from the Ministry of Trade, Industry \& Energy (MOTIE) of Korea, within the Global Excellence Technology Innovation (Grant No. 10045029).

\section{REFERENCES}

1. J.J. Becker, M.A. Madden, T.T. Natarajan, T.J. Piccone, E.J. Serrano, S.R. Story, S.C. Ecklund-Baker, I.A. Nickerson, and W.K. Schlichting: AISTech 2005 Conf. Proc., vol. II, Association for Iron \& Steel Technology, Charlotte, NC, 2005, pp. 99-106.

2. S. Street, K. James, N. Minor, A. Roelant, and J. Tremp: Iron Steel Technol., 2008, vol. 5, pp. 38-49.

3. K. Blazek, H.B. Yin, G. Skoczylas, M. McClymonds, and M. Frazee: Iron Steel Technol., 2011, vol. 8, pp. 232-40.

4. W.L. Wang, K. Blazek, and A. Cramb: Metall. Mater. Trans. B., 2008, vol. 39B, pp. 66-74.

5. Z. Zhang, G. Wen, and P. Tang: ISIJ Int., 2008, vol. 48, pp. 739 46.

6. K. Kinoshita, Y. Yoshii, and H. Kitaoka: J. Met., 1984, vol. 36, pp. 38-43.

7. J. Liao, Y. Zhang, S. Sridhar, X. Wang, and Z. Zhang: ISIJ Int., 2012, vol. 52, pp. 753-58.

8. J.W. Cho, K. Blazek, M. Frazee, H.B. Yin, J.H. Park, and S.W. Moon: ISIJ Int., 2013, vol. 53, pp. 62-70.

9. T. Wu, Q. Wang, S. He, J. Xu, X. Long, and Y. Lu: Steel Res. Int., 2012, vol. 83, pp. 1194-02.

10. W. Yan, W. Chen, Y. Yang, C. Lippold, and A. Mclean: ISIJ Int., 2015, vol. 55, pp. 1000-09.

11. B. Jiang, W. Wang, I. Sohn, J. Wei, L. Zhou, and B. Lu: Mater. Trans. B., 2014, vol. 45B, pp. 1057-67.

12. G.H. Kim, C.S. Kim, and I. Sohn: ISIJ Int., 2013, vol. 53, pp. 170 76.

13. M.D. Seo, C.B. Shi, J.W. Cho, and S.H. Kim: Metall. Mater. Trans. B., 2014, vol. 45B, pp. $1874-86$.
14. M.D. Seo, C.B. Shi, J.Y. Baek, J.W. Cho, and S.H. Kim: Metall. Mater. Trans. B., 2015, vol. 46B, pp. 1-10.

15. C.B. Shi, M.D. Seo, H. Wang, J.W. Cho, and S.H. Kim: Metall. Mater. Trans. B., 2014, vol. 45B, pp. 1081-97.

16. C.B. Shi, M.D. Seo, H. Wang, J.W. Cho, and S.H. Kim: Metall. Mater. Trans. B, 2015, vol. 46B, pp. 345-56.

17. K.A. Jackson: Growth and Perfection of Crystals, Wiley, New York, 1958, pp. 319-24.

18. K.A. Jackson: Liquid Metals and Solidification, ASM, Cleveland, $\mathrm{OH}, 1958$, pp. 174-86.

19. J.P. van der Eerden: Phys. Rev. B, 1976, vol. 13, p. 4942.

20. J.P. Weeks and G H Gilmer: in Advances in Chemical Physics, I. Prigogine and S.A. Rice, eds., Wiley, New York, vol. 40, 1979, pp. 157.

21. M.R. Taylor, R.S. Fidler, and R.W. Smith: Metall. Trans. A, 1971, vol. 2, pp. 1793-98.

22. R.S. Fidler, M.N. Croker, and R.W. Smith: J. Cryst. Growth, 1972, vol. 13 (14), pp. 739-46.

23. O.E. Temkin: Sov. Phys. Cryst., 1971, vol. 15, pp. 767-72.

24. O.E. Temkin: Sov. Phys. Cryst., 1971, vol. 15, pp. 773-80.

25. Y. Lu, G. Yang, F. Liu, H. Wang, and Y. Zhou: Europhys. Lett., 2006, vol. 74, pp. 281-86.

26. J. Heulens, B. Blanpain, and N. Moelans: J. Eur. Ceram. Soc., 2011, vol. 31, pp. 1873-79.

27. D. Li and D.M. Herlach: Phys. Rev. Lett., 1996, vol. 77, p. 1801.

28. P.V. Evans, S. Vitta, R.G. Hamerton, and A.L. Greer: Acta Metall. Mater., 1990, vol. 38, pp. 233-42.

29. K.A. Jackson: J. Cryst. Growth., 2004, vol. 264, pp. 519-29.

30. K.A. Jackson, D.R. Uhlmann, and J.D. Hunt: J. Cryst. Growth., 1967, vol. 1, pp. 1-36.

31. J.M. Schultz: Polymer Material Science, Prentice Hall, Englewood, 1974.

32. D. Nassyrov and I.H. Jung: A Model for Slag Solidification, AISTech, Indianapolis, 2014, pp. 1669-80.

33. P.W. Arkins: Physical Chemistry, Oxford University Press, Oxford, 1978.

34. I. Barin and O. Knacke: Thermochemical Properties of Inorganic Substances, Springer, Berlin, 1973

35. I. Barin and O. Knacke: Thermochemical Properties of Inorganic Substances, Supplement, Springer, Berlin, 1977.

36. R.J. Kirkpatrick: Am. Mineral., 1975, vol. 60, pp. 798-814

37. S.H. Shin, J.W. Cho, and S.H. Kim: J. Am. Ceram. Soc., 2014, vol. 97 , pp. 3263-69.

38. H. Liu, G. Wen, and P. Tang: ISIJ Int., 2009, vol. 49, pp. 843-50.

39. M.D. Seo, C.B. Shi, H. Wang, J.W. Cho, and S.H. Kim: $J$. Non-Cryst. Solids, 2015, vol. 412, pp. 58-65.

40. L. Zhou, W. Wang, F. Ma, J. Li, J. Wei, and H. Matsuura: Metall. Mater. Trans. B., 2012, vol. 43B, pp. 354-62.

41. Z. Wang, Q. Shu, and K. Chou: ISIJ. Int., 2015, vol. 55, pp. 70916. 